Document downloaded from:

http://hdl.handle.net/10251/142275

This paper must be cited as:

Martirena, F.; Monzó Balbuena, JM. (12-2). Vegetable ashes as Supplementary Cementitious Materials. Cement and Concrete Research. 114:57-64. https://doi.org/10.1016/j.cemconres.2017.08.015

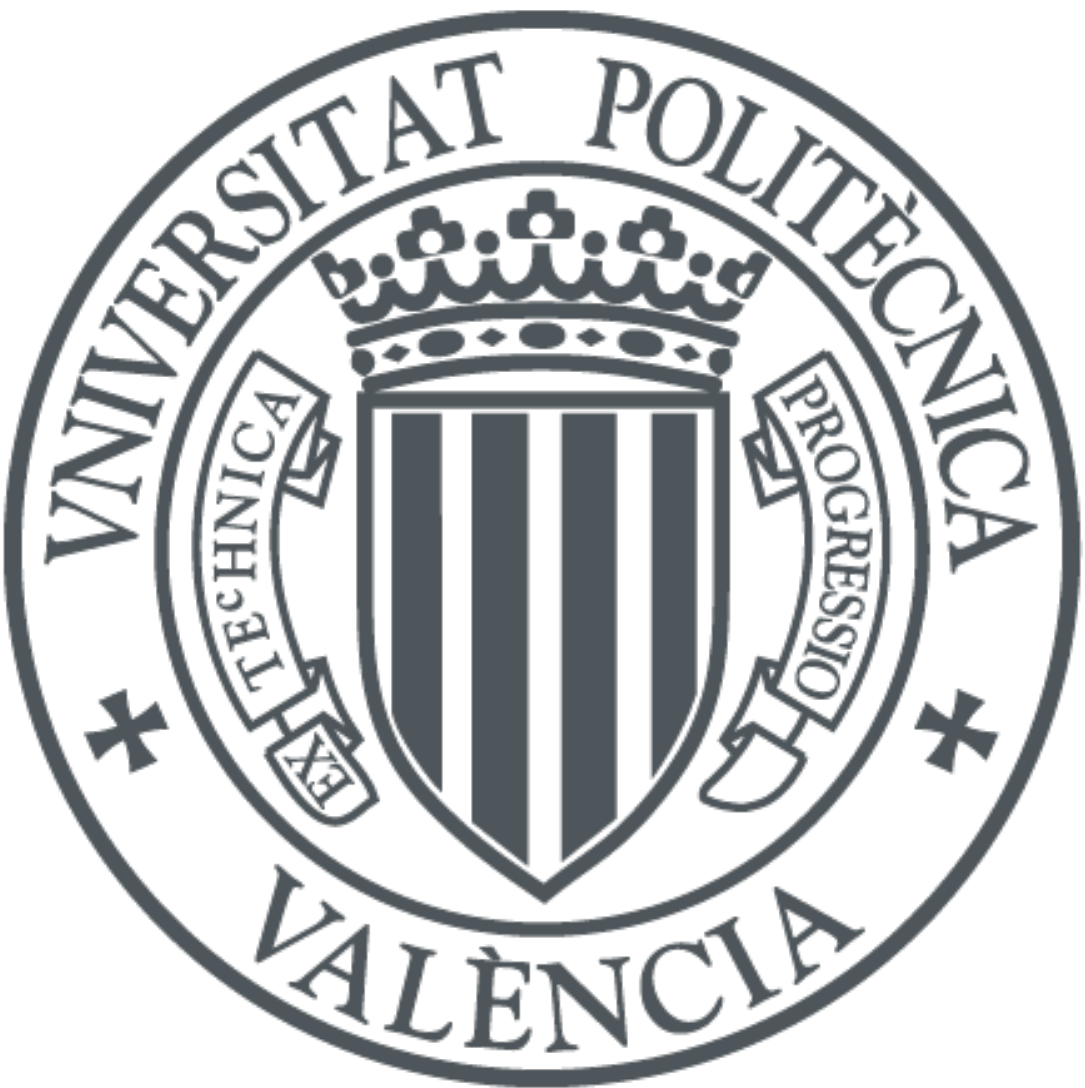

The final publication is available at

https://doi.org/10.1016/j.cemconres.2017.08.015

Copyright Elsevier

Additional Information 


\title{
Vegetable ashes as Supplementary Cementitious Materials
}

\author{
Martirena F. ${ }^{1}$, Monzó J. ${ }^{2}$ \\ ${ }^{1}$ Universidad Central de las Villas, Santa Clara, Cuba, f.martirena@enet.cu, \\ ${ }^{2}$ Instituto de Ciencia y Tecnología del Hormigón. Universidat Politècnica de Valencia, \\ Spain; jmmonzo@cst.upv.es
}

\begin{abstract}
Approximately 140 billion metric tons of biomass are produced every year in the world from agriculture. The ashes resulting from firing agricultural wastes such as rice husk, sugar cane and others can be used as Supplementary Cementitious Materials (SCM). They can be mixed with lime alone or in ternary mixtures with Portland cement and lime. If fired at temperatures around $600-700{ }^{\circ} \mathrm{C}$ the agricultural ashes exhibit good reactivity. Despite extensive research work carried out on the use of agricultural ashes as source of SCMs, few success stories are reported on practical applications on an industrial scale. Details of the firing technology should be re-assessed, with special emphasis on the scale at which the technology begins to be economically suitable. Further research is also needed to understand the mechanisms of structural transformation of amorphous silica during calcination, and the impact of the ashes on cement hydration in blended systems.
\end{abstract}

\section{Introduction}

Approximately 140 billion metric tons of biomass are produced every year in the world from agriculture [1]. Widely available, renewable, and virtually free, waste biomass is an important resource. This volume of biomass can be converted to an enormous amount of energy and raw materials. Equivalent to approximately 50 billion tons of oil [2], agricultural biomass waste converted to energy could substantially offset fossil fuels, reduce greenhouse gases emissions and provide sources for renewable energy.

Residues from crops take the form of residual stalks, straw, leaves, roots, husk, nut or seed shells, waste wood and animal husbandry waste. Annual availability of residue is in the range of 3.7 billion tonnes [3]. The major quantity of wastes generated from agricultural sources are sugarcane bagasse, paddy and wheat straw and husk, wastes of vegetables, food products, tea, and oil production [4]. Due to industrial processing, these bio-wastes are fired and the remaining ashes are generally at present considered a waste.

There are reports of the use of vegetable ashes in cementitious systems, either mixed with lime alone [5] or in ternary mixtures with Portland cement and lime [6]. There is, however, a general lack of fundamental understanding of the mechanisms for hydration of agricultural wastes as pozzolan, despite the extensive research work carried out. Further, technological and industrial challenges have not been addressed in a comprehensive way.

This paper aims at reviewing the research and innovation work carried out on the use of a great variety of ashes of vegetable wastes as cement substitutes in the production of concrete. 


\section{Technology presentation}

\subsection{Description}

The principle behind the pozzolanic reaction of agricultural wastes is the reaction of reactive $\mathrm{SiO}_{2}$ present in the ash with calcium hydroxide formed during cement reaction, as described in equations (1) and (2) to form further hydrates. This enables cement substitution by the pozzolanic material. Normal substitution rates are up to $30 \%$ of cement (wt.) although this data depends on the type and characteristics of the pozzolan.[7]

$2\left(3 \mathrm{CaO} \cdot \mathrm{SiO}_{2}\right)+6 \mathrm{H}_{2} \mathrm{O} \rightarrow 3 \mathrm{CaO} \cdot 2 \mathrm{SiO}_{2} \cdot 3 \mathrm{H}_{2} \mathrm{O}+3 \mathrm{Ca}(\mathrm{OH})_{2}$

$2\left(2 \mathrm{CaO} \cdot \mathrm{SiO}_{2}\right)+4 \mathrm{H} 2 \mathrm{O} \rightarrow 3 \mathrm{CaO} \cdot 2 \mathrm{SiO}_{2} \cdot 3 \mathrm{H}_{2} \mathrm{O}+\mathrm{Ca}(\mathrm{OH})_{2}$

Another alternative could be to combine pozzolan with slaked lime $\left(\mathrm{Ca}(\mathrm{OH})_{2}\right)$ obtained from the hydration of quicklime $(\mathrm{CaO})[8]$

The bio-silica $\left(\mathrm{SiO}_{2}\right)$ in agricultural wastes comes from concentrating it through firing. There are plants that are known to bear amorphous silica in their structure. Figure 1 shows the ash percentage and the silica content of this for several plants; the best choice would be to have a high silica content and high ash percentage. The most commonly used crop wastes are rice husks, sugar cane bagasse or straw (leaves of the sugar cane which are removed as part of industrial processing), and to a less extent others such as wheat and bamboo. $[9,10]$

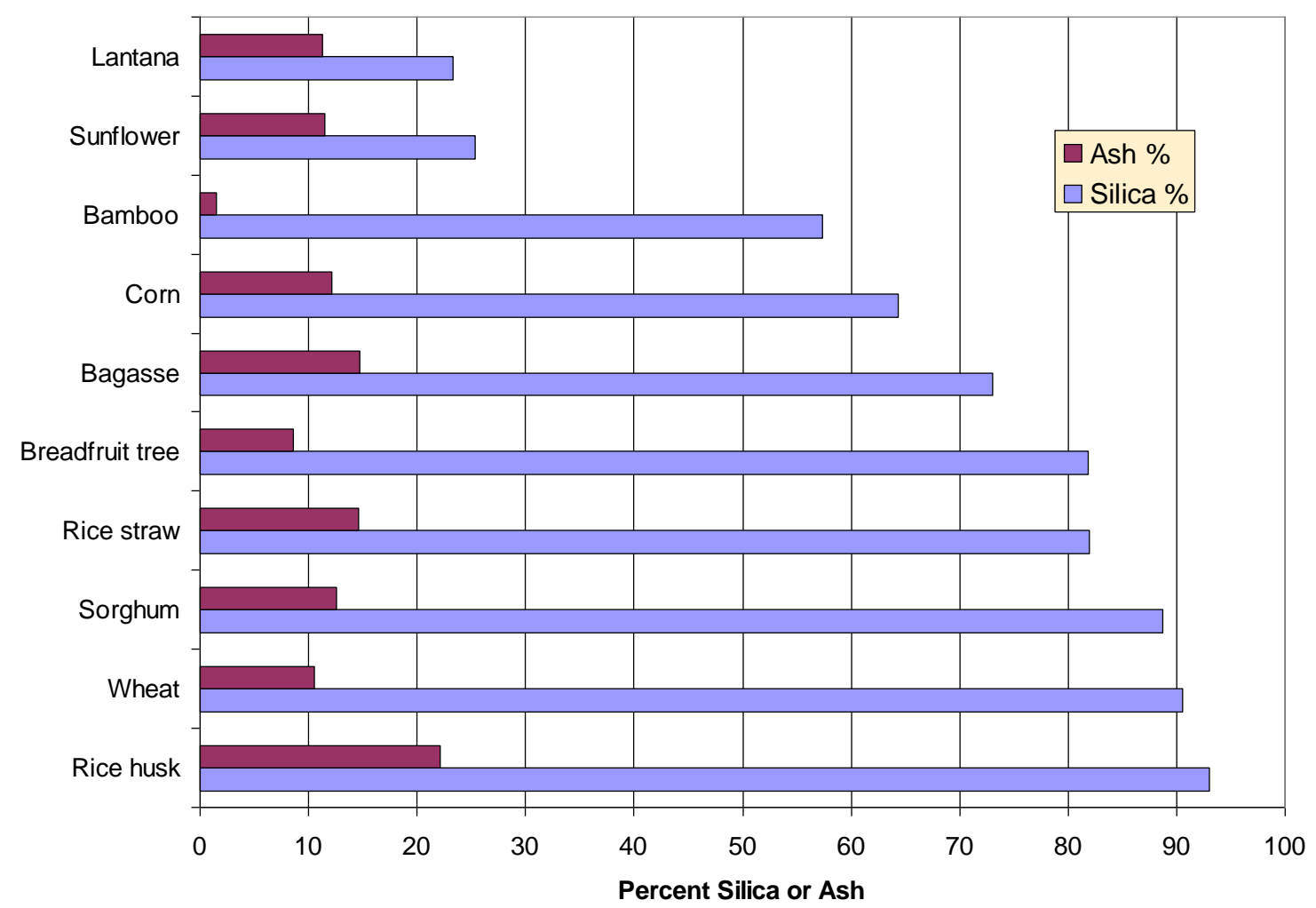

Figure 1: Amount of amorphous silica and ashes in crops $[9,10]$

The agricultural ashes exhibit good reactivity when the silica occurs in an amorphous form. This happens if the material is fired at temperatures around $600-700{ }^{\circ} \mathrm{C}$, where silica remains amorphous; it can be clearly identified by the hump in the $\mathrm{X}$ ray diffraction diagram as presented in Figure 2. If the temperature 
goes above $700{ }^{\circ} \mathrm{C}$, silica starts to occur as crystalline phases whose phase composition depends on the firing temperature and the cooling regime $[11,12,13]$.

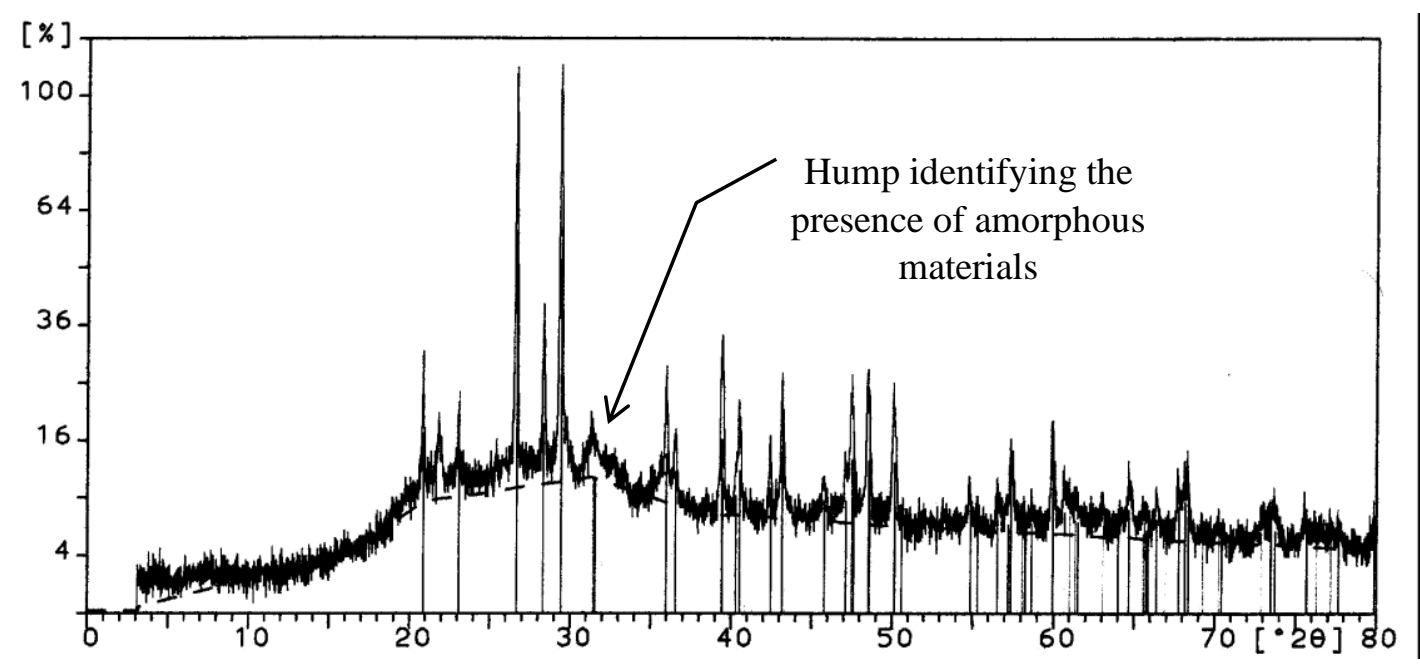

Figure 2: identification of amorphous material at XRD diagram, agriculture ash [8]

Rice husk ash is by far the most studied material. The husks of the rice plant contain a significant amount of silica. During firing, the silica is concentrated to levels above $90 \% \mathrm{wt}$. in the ash, thus enabling the production of a material with great potential reactivity [14]. The husks are used as fuel in industrial boilers coupled to power generation units, but they are also fired under various other conditions, such as incinerators, or even in open pit fires $[15,16]$. The reactivity of the rice husk ash depends on the amount of amorphous silicon present and its specific surface. [17]

Wastes from sugar production are the second most studied materials. Depending on the industrial processing of the plant there are two main wastes: bagasse and waste leaves. Bagasse is produced through squeezing the stalks, while the waste leaves are collected and processed at pre-processing plants prior to bringing the sugar cane to the industrial mills.

Bagasse is often used as fuel in co-generation processes associated with the sugar industry. The fuel is fired at the boilers of the sugar refinery, and ashes are collected as waste. Depending on the efficiency of the system, the ashes can contain greater or lesser amounts of unburnt material, which compromises reactivity. In normal boilers, the temperature of the firing chamber is above $1200{ }^{\circ} \mathrm{C}$, thus the resulting ash is rich in crystalline phases such as quartz and cristoballite, which are less reactive [8]. However, a study on sugar cane wastes shows that sugar cane bagasse ash can yet yield good results when fired at temperatures in the range $800-1000{ }^{\circ} \mathrm{C}$, which are closer to the actual temperatures at boilers, and sugar cane leaves ash did not prove to be sensitive to temperature. [18]

The fall in reactivity in co-generation ashes resulting from sugar cane wastes could be related to contaminants introduced in the system during harvesting and handling of the wastes. The presence of coarse quartz particles is reported both in ashes collected at the boilers and at the cyclones. If these quartz particles could be removed, the reactivity of the resulting material could be enhanced. [19]

If firing takes place at lower temperature and controlled residence time, the resulting ashes have more amorphous silica, however lower temperatures compromise the efficiency of the material as a fuel. Figure 3 shows XRD diagrams of sugar cane straw ash ash fired at an industrial boiler (SCSA) and under 
controlled conditions at an incinerator (ASH1 and ASH2). High firing temperature favors formation of high temperature silica phases such as cristoballite, which compromise the reactivity of the material.

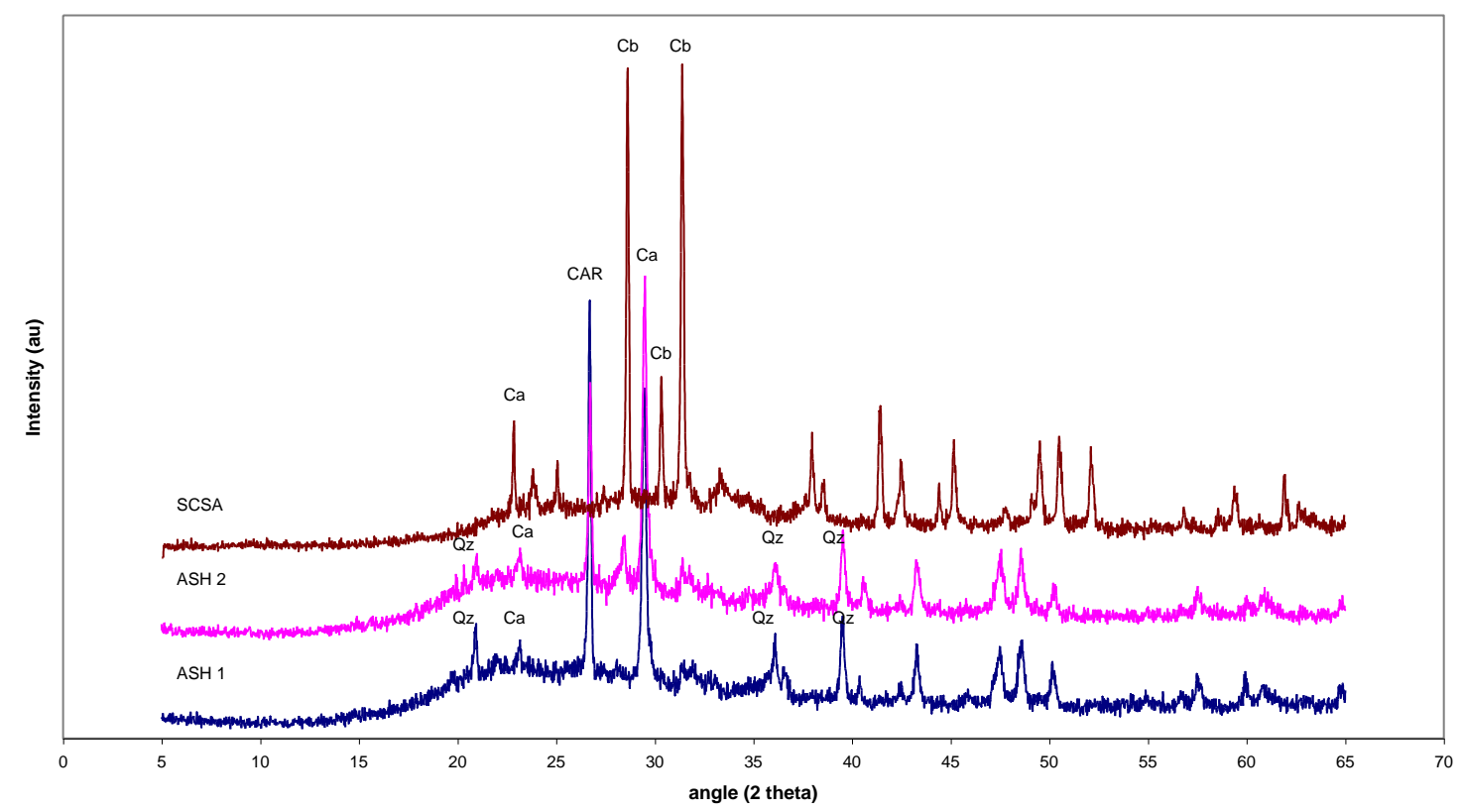

Figure 3: XRD diagrams of cane straw ash fired at industrial boilers and under controlled temperature [21]. Legend: $\mathrm{Cb}$, cristoballite; CAR, carbon; Ca, calcite; Qz, quartz; SCBA, sugar cane bagasse ash; ASH 1, sugar cane straw ash 1; ASH 2, sugar cane straw ash 2

Rice husk ash has been used as cement substitute in cementitious systems in proportions between 0-30\% by mass. The high internal porosity of rice husk ash prompts an increase in water demand in fresh concrete, thus affecting the rheology. The optimal level for concrete replacement is around $0-20 \%$ by mass. In these proportions, addition of rice husk ash can increase up to $20 \%$ of the strength of concrete. Further substitutions are hindered by the high water demand of the system. If properly treated and finely ground, rice husk ash can be used as mineral admixture for the production of high strength concrete [20].

Among other vegetable ashes, wheat ash has received some attention. The main waste of wheat is the straw, which contains high amounts of silica, especially in the leaves. If fired under controlled conditions, wheat straw shows good pozzolanic reactivity. [9]

Processing technology is crucial in terms of producing a good product. The following technologies are most commonly used:

- Industrial boilers, which use biomass as fuel. The sugar industry and power generation industry are the main users of agricultural wastes. Bottom and fly ash are produced as waste of this process.

- Rotary clinker kilns, which can use biomass pellets as alternative fuels. The pellets are fed directly to the cement kiln and fired at temperatures around $1500 \mathrm{C}$. The ashes can complement the chemical and mineralogical composition of clinker. [22] 
- Fluidized bed boilers, with different pre-processing procedures for biomass. These facilities can operate at lower temperature and high combustion efficiency. The properties of the resulting ash depend on how it was processed prior to firing [23,24,25].

- Rudimentary incinerators. Several ideas have been developed to produce reactive ash in incinerators [21]. The proposals have a low level of mechanization and thus a very low output of ash. Further, the relatively low firing temperature does not allow coupling with co-generation systems.

- Open pit firing. This is a very common way of disposing agricultural wastes in developing countries. The properties of ash are not homogeneous over time, and the amount of carbon is normally very high, depending on oxidizing conditions [25]. Further, open pit firing is an important source for black smoke, and thus raises environmental concerns [25].

Vegetable ashes are considered suitable for use as Supplementary Cementitious Materials if:

- Its chemical composition meets ASTM C 618 "Standard Specification for Coal Fly Ash and Raw or Calcined Natural Pozzolan for Use as a Mineral Admixture in Concrete" requirements, that is, the sum of $\mathrm{SiO}_{2}+\mathrm{Al}_{2} \mathrm{O}_{3}+\mathrm{Fe}_{2} \mathrm{O}_{3}>70 \%$ for $\mathrm{N}$ type pozzolans. Table 1 shows typical chemical composition of rice husk and sugar cane ashes compared to pulverized coal fly ash.

- If, by any means, evidence of the occurrence of pozzolanic reaction is proven. Calcium hydroxide consumption in lime-pozzolan systems is a good indicator, and it can be measured directly at thermo-gravimetric diagram [7], or estimated by conductimetry [27]. Compressive strength of Portland cement-pozzolan systems is by far the most effective way of proving the reactivity; there are several standards that consider these methods. [28] There are other indirect methods of assessing reactivity which could also be suitable for vegetable ashes.[13,29].

Table 1: Typical chemical compositions of agricultural ashes $[7,8]$

\begin{tabular}{|l|c|c|c|c|}
\hline & Coal ash & $\begin{array}{c}\text { Rice husk } \\
\text { ash }\end{array}$ & $\begin{array}{c}\text { Bagasse } \\
\text { ash }\end{array}$ & Straw ash \\
\hline $\mathrm{SiO}_{2}$ & 56.3 & 71.74 & 72.74 & 59.06 \\
\hline $\mathrm{Al}_{2} \mathrm{O}_{3}$ & 30.1 & 5.61 & 5.26 & 4.75 \\
\hline $\mathrm{Fe}_{2} \mathrm{O}_{3}$ & 6.41 & 3.47 & 3.92 & 3.18 \\
\hline $\mathrm{TiO}_{2}$ & - & 0.38 & 0.32 & 0.34 \\
\hline $\mathrm{CaO}$ & 1.16 & 10.42 & 7.99 & 19.59 \\
\hline $\mathrm{MgO}$ & 0.8 & 1.98 & 2.78 & 2.25 \\
\hline $\mathrm{SO}_{3}$ & 0.26 & 0.5 & 0.13 & 1.37 \\
\hline $\mathrm{K}_{2} \mathrm{O}$ & 0.73 & 3.62 & 3.47 & 4.75 \\
\hline $\mathrm{Na}_{2} \mathrm{O}$ & 0.07 & 0.4 & 0.84 & 0.73 \\
\hline $\mathrm{P}_{2} \mathrm{O}_{5}$ & & 0.89 & 1.59 & 1.67 \\
\hline $\mathrm{LOI}$ & 4.43 & 0.78 & 0.77 & 2.05 \\
\hline
\end{tabular}

The main applications of agricultural wastes as fuel in industrial processes are:

- Direct firing in waste-to-energy plants without any chemicals processing to produce steam for making electricity. Also biomass can be burned to provide heat for industries and homes

- Firing biomass pellets in cement kilns for the production of clinker. The density of the biomass is increased by pressing into pellets, to minimise the transport problem. The pellets are fed to the kilns and used as alternative fuel for clinker production. Modern kiln technologies allow the use 
of low calorific value fuels like biomass $(10-18 \mathrm{GJ} / \mathrm{t})$. The ash resulting from firing biomass will be integrated in the chemical and mineralogical composition of clinker and will provide extra sources of silica and alumina for clinker. A large amount of fossil based fuel can be replaced with a positive impact on carbon emissions [22,30].

- Pyrolysis of agriculture wastes to convert biomass to a more useful fuel such as hydrocarbon rich gas mixture and a carbon rich solid residue. Typical gas composition of biomass pyrolysis includes $\mathrm{CO}, \mathrm{CO}_{2}, \mathrm{CH}_{4}$ and $\mathrm{H}_{2}$ as major products along with other organic compounds. Usually, fast pyrolysis yields more gases than solids [31].

- Gasification of agriculture wastes into gaseous fuels by means of partial oxidation of the biomass at high temperatures. This process also allows for the production of methanol or hydrogen, each of which may have a good future as fuels [31].

With the exception of using pellets in clinker production, the rest of the industrial processes not closely linked to the production of cement and concrete. This would compromise further use of the wastes in cement or concrete due to the complexities of relationships between distant industries and cost of transportation.

The main applications reported for the ashes resulting from firing agriculture wastes as Supplementary Cementitious Materials far are:

- Lime-agriculture ash binder alone, for low strength applications in rural, small scale production facilities. There are abundant examples in Asia, where properties of the binder have been assessed aided by the Indian standard IS 4098. [32] Strength of standard mortars at 7 days is expected to be above $2 \mathrm{MPa}$, and 28 days strength should be higher than $4 \mathrm{MPa}$.[15,33]

- Agricultural ashes used as pozzolan alone in blended cement systems. There are experiences on the use of Rice Husk Ash and Bagasse Ash as mineral admixtures in concrete. Up to $30 \%$ of Portland cement can be replaced for an acceptable performance of cement $[33,34]$.

\subsection{Robustness of the technology}

Despite the extensive research work carried out on the use of agricultural ashes as source of Supplementary Cementitious Materials, very few success stories are reported on practical applications in the industry. The main reasons are:

- The agricultural ashes have a very low density, and a scattered geographic distribution, which makes transport costly. The material has to be transported large distances before it can be processed, this can also adversely impact on the carbon footprint of the material.

- There is no mainstream machinery available for processing agricultural wastes, and the existing systems are not optimized, thus resulting in high production costs and variable quality.

- The density of the ashes ranges between $2.0-2.5 \mathrm{~g} / \mathrm{cm}^{3}, 25 \%$ lighter than Portland cement, thus, if cement substitutions are calculated in weight, the volume of fines in concrete increases significantly and rheology of the system could be compromised. This situation could be tackled by ultra-fine grinding the ashes, in order to destroy the porous structure and increase density. There are reports of this practice in Brazil, and it has been proven that ultrafine bagasse ash improves rheology of cementitious systems [11]. However in this case the grinding energy wouly also need to be accounted for.

- There are great differences between facilities where the agricultural wastes can be fired, and this impacts the quality of the ash, especially the content of organic material unburnt or partially burnt. This could compromise consistency of the properties of the material for bulky deliveries. 
- Improper firing could lead to black smoke formation, one of the main causes for accelerating Global Warming [26]

Some of the obstacles to the widespread use of agricultural ashes in cementitious materials are discussed in Table 2.

Table 2: Obstacles to the widespread use of agricultural ashes

\begin{tabular}{|c|c|c|c|c|}
\hline Is the technology suitable & Unknown & $\begin{array}{l}\text { Proved } \\
\text { Possible }\end{array}$ & $\begin{array}{c}\text { Needs } \\
\text { further } \\
\text { development }\end{array}$ & $\begin{array}{c}\text { Not } \\
\text { possible }\end{array}$ \\
\hline 1) Use in poor and remote regions, & & & $\mathrm{x}$ & \\
\hline 2) By for illiterate worker & & $\mathrm{x}$ & & \\
\hline 3) Lack or poor control of aggregates, & $\mathrm{x}$ & & & \\
\hline 4) Poor control of water content, & & & $\mathrm{x}$ & \\
\hline 5) Possible to use without admixtures & & & $\mathrm{x}$ & \\
\hline 6) hot climates & & $\mathrm{x}$ & & \\
\hline $\begin{array}{l}\text { 7) Stability of workability at high } \\
\text { temperatures }\end{array}$ & & & $\mathrm{x}$ & \\
\hline 8) High strength at early ages (precast) & & & $\mathrm{x}$ & \\
\hline 9) Sensitivity to common contamination & $\mathrm{X}$ & & & \\
\hline
\end{tabular}

Further, the problems associated with the distribution, cost and quality of the product may favour alternative uses for the ashes of agriculture wastes, such as soil fertilizers. There are reports on fertilization of soil with granulated biomass ash, which changed soil chemical properties, altered understory vegetation, increased tree growth and decomposition rate but there were no significant changes in the $\mathrm{N}_{2} \mathrm{O}$ and $\mathrm{CH}_{4}$ fluxes in situ. Results show that there is no major risk of increasing GHG emissions with the use of granulated wood-ash as a fertiliser. [36,37,38,39]

\section{Durability of the technology}

There are reports of reduction of permeability of concrete for additions of rice husk ash in the range of $10-30 \%$ by mass. A decrease in sorptivity of the concrete is also described. A decrease of $80-90 \%$ of chloride ion ingress and a reduction in the coefficient of diffusion is also reported for these levels of substitution $[40,41]$. The improvement in the pore structure of the cementitious matrix is associated with pore refinement due to the contribution of the pozzolanic reaction. The total porosity of the system is generally higher in blended systems, but the fraction of smaller pores increases with the pozzolanic reaction.

Figure 4 presents results of Mercury Intrusion Porosimetry in pastes made with a blend of Portland cement and a 1:3 mixture of lime and sugar cane straw ash. The blended systems have a higher total porosity compared with pure Portland cement system at all ages. However, at 60 days the threshold pore entry for the blend is smaller than that of Portland cement, thus indicating a pore refining effect similar to what occurs in other pozzolanic systems [42] 


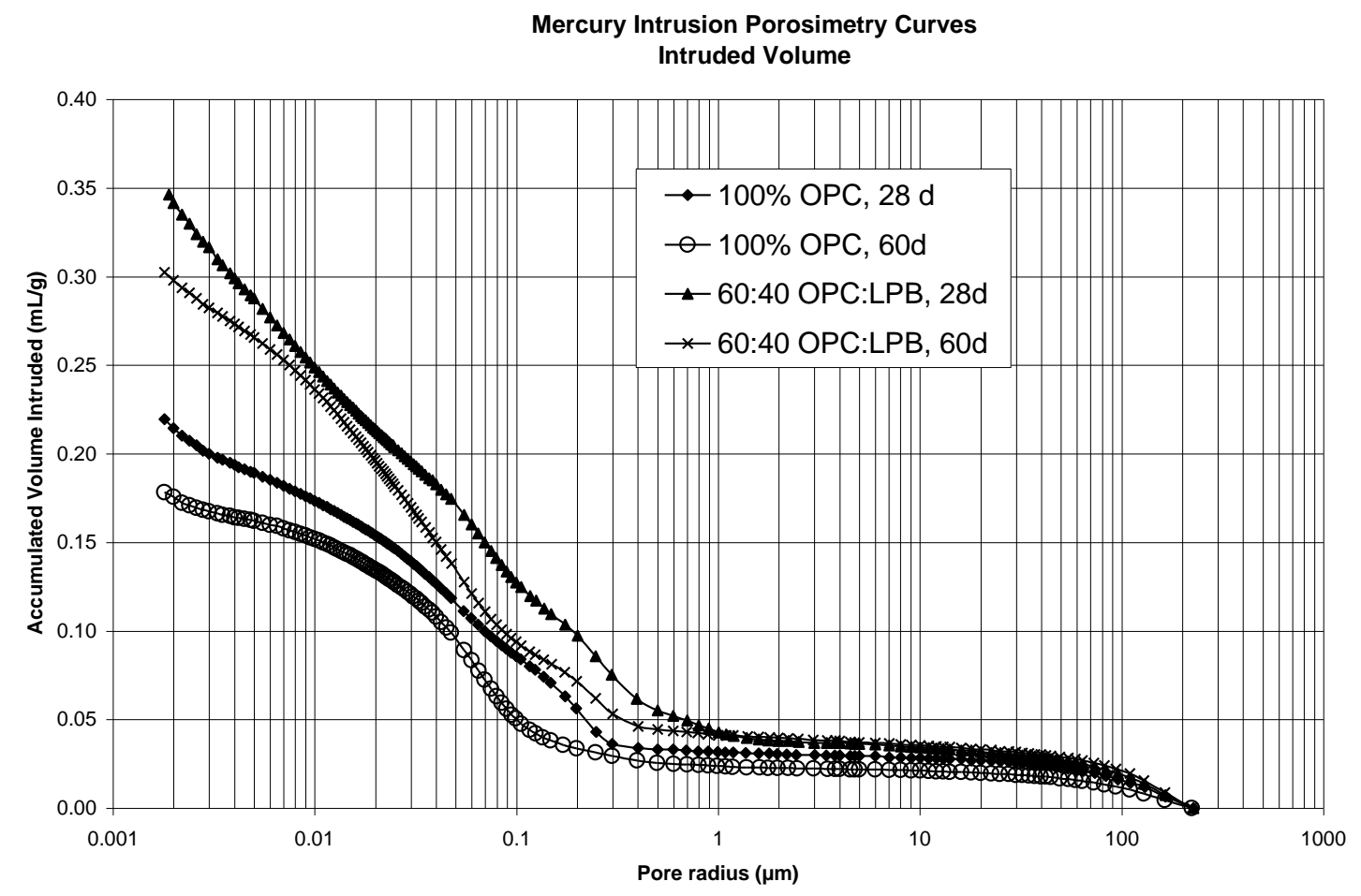

Fig. 4: Mercury Intrusion Porosimetry of pastes made with Portland cement and a blend of Portland cement and lime-sugar cane bagasse ash: (i) 100\% Portland cement at 28 and 60 days, and (ii) A blend of $60 \%$ Portland cement and $40 \%$ of a a mixture of 3 parts of bagasse ash and 1 part of lime at 28 and 60 days [6]

The issue of durability of cementitious systems containing vegetable wastes ashes has, however, not been extensively addressed in the literature, probably because of the few practical application of the technology. Experimental data about performance of these systems exposed to chloride, sulfate acidic attack and carbonation is needed if such materials are to be used in practice.

\section{Stage of development and research needs}

Table 3 characterizes the current state of development of technologies associated with recycling agricultural wastes through firing.

Table 3: Current state of development of technologies associated with recycling agricultural wastes through firing

\begin{tabular}{|l|l|c|}
\hline Innovation Phase & 1) Conceptual phase & $\mathrm{X}$ \\
\hline & 2) Laboratory evidence & \\
\hline & a) Unanimous & $\mathrm{x}$ \\
\hline & b) Some debate & $\mathrm{X}$ \\
\hline & c) Important debate on fundamental issues & \\
\hline Demonstration & 3) Pilot plant & $\mathrm{X}$ \\
\hline Public Policy & 4) Standardization & \\
\hline & a) One country & \\
\hline & b) Some countries & \\
\hline & c) International & \\
\hline
\end{tabular}




\begin{tabular}{|l|l|c|}
\hline Market Penetration & 5) Commercial & \\
\hline & a) One company, one site & \\
\hline & b) One company, many countries & \\
\hline & c) Few companies, several countries & $\mathrm{x}$ \\
\hline & d) Widely known & \\
\hline
\end{tabular}

There are great gaps in terms of technology for firing the agricultural wastes, waste pelletisation and others.

\subsection{Patent protection}

There is a patent approved on Sep. 13, 1994 under the name "Highly Durable Cement Products Containing Siliceous Ashes", Patent Number: US005346548A; allocated to Povindar K. Mehta, El Cerrito, Calif., from the Regents of the University of California, Oakland, Calif. [43] This patent has currently expired, according to US patent protection rules.

It describes the use of a siliceous ash, obtained from the burning of crop residues such as rice hull (also called rice husk), which is used as a mineral addition to cement. Mineral additions may be blended or interground with cement, or added directly to compositions comprising cement (e.g., concrete or mortar) before or during mixing.

The siliceous ash from crop residue used as a mineral addition typically comprises about $60-95 \%$ by weight silica. There is provided a composition comprising at least one hydraulic cement and from about $5-30 \%$ by weight, preferably about $10-30 \%$ by weight, of said cement of siliceous ash from crop residue. The terms "cement" and "hydraulic cement" refer both to various types of Portland cement, and to compositions commonly referred to in the art as blended Portland cements

The claims of the patent are:

1. Novel blends of crop residue siliceous ash and cement are provided.

2. Novel concrete and mortar products having high strength and low or very low permeability to water and chloride ions are provided.

3. To provide a method for decreasing the water and chloride ion permeability of concrete and mortar compositions.

4. To provide a method for accelerating the early strength of concrete compositions containing fly ash.

\section{Potential of scalability}

The technology could be scaled up in countries with intensive agriculture, especially in the areas of rice and sugar production. However, details of the technology need to be re-assessed, with emphasis on the scale at which the technology begins to be economically suitable.

There are still some issues which would need to be addressed:

- Increasing density of the original product through packing, for instance, in pellets or briquettes. There is plenty of technology commercially available which can be implemented [40].

- Using biomass pellets as alternative fuel in cement production. This demands transfer of technologies to use low calorific value fuels like biomass [30].

- Development of low temperature industrial devices like fluidized bed boilers, where biomass can be fired under $750{ }^{\circ} \mathrm{C}$ to maintain pozzolanic reactivity and yet achieve high energy efficiency $[23,25,44,45]$. 
- Understand the hydration mechanisms in cementitious systems, and perform trials of concrete made with agricultural ashes subjected to aggressive conditions [46].

- Understand the nature of the emissions associated with firing biomass and the ones offset during photosynthesis through realistic databases [24,47].

\subsection{Raw materials}

Biomass fuels can be produced from agricultural, forestry and municipal wastes and residues, as well as from crops such as sugar, grain, and vegetable oil. Crops grown for use as biomass fuel can be grown on degraded, surplus and marginal agricultural land, and algae could, in the future, be exploited as a marine source of biomass fuel. Bioenergy is the largest global source of renewable energy, and contributes an estimated $10 \%$ of global primary energy production, in particular as a direct source of industrial and domestic heat.[48]

In 2008, global primary energy supply and consumption was approximately 550 EJ. Modern bio-energy, used to supply heat, power and transport fuels, accounted for around 2\% ( 11 EJ).The remainder ( 8\%, $\sim 40$ EJ) comprised traditional uses of biomass including wood straw and charcoal used for cooking and heating. The contribution from energy crops is correspondingly low 8-71 EJ. The contribution from wastes and residues is not considered in all studies, but where included the net contribution is in the range 17-30 EJ. [49].

Huge reserves of rice husk are reported, in Asian countries and North America. In India, for instance, it is reported that about $600 \mathrm{MT}$ of agriculture wastes have been generated from agricultural sources alone. If fired during industrial processing, for average losses on ignition of 7\%, 42 MT of ashes could be produced in one year; approximately $15 \%$ of India's cement production. During the harvest season of sugar cane in Cuba, an average of 70 million tonnes of sugar cane are harvested, which yields 21 million tonnes bagasse; if all bagasse is properly fired, 1.5 million tonnes of bagasse ash could be produced, which is roughly $80 \%$ of Cuba's cement production [50]. Some of these ashes have been reported to have good pozzolanic properties [32,34,51,52], so they could eventually be used as Supplementary

Cementitious Materials in cement and concrete.

\section{Comparison with OPC}

\subsection{Production process}

Sugar and rice industry could be -because of their abundant reserves of biomass- the candidates for massive production of vegetable ashes suitable to be used as Supplementary Cementitious Materials. This demands, however, for significant changes in the technology for firing at the boilers, in order to produce an ash fired at optimal conditions in terms of temperature, residence time and carbon content. The most promising technology is the fluidized bed boilers, because it can operate at relatively low temperatures where the ash remains amorphous and thus reactive $[1,23,24,53]$

The choices for using agricultural ashes in cementitious systems are as follow:

- Addition during cement manufacture at cement plant. This implies some investment in creating facilities for storing the ashes, and also a link between agriculture and the cement makers for the supply of the material. The main hurdle is to guarantee the quality of the material at a suitable price for the industry.

- Addition at the concrete mixer as a mineral addition. This seems to be a better alternative for the industry. Currently, industries such as sugar and rice, which produce large amounts of agriculture wastes, do not have strong links with construction, and the investment process required could be 
seen as a financial burden for their main production. Improving the quality of the production of vegetable ashes involves processes such as super fine grinding and ash washing [11]

\subsection{Materials processing and application}

The main applications so far have been experimental production of binders and concrete where reactive ashes have been used. Blended cement similar to normal Portland-pozzolan cement have been tested. The main problems found are the following: $[10,28,54]$

- Increase in water demand for concrete, due to the highly porous nature of the addition and the increase of the volume of fines due to the presence of a much lighter material. This can be compensated with the use of superplasticizers or by ultra-fine grinding of the ash to destroy the organic structure $[11,35,55]$.

- Reduction of reactivity of the ash and poor performance with admixtures, related with the presence of organic carbon due to improper combustion $[8,35]$.

- Potential impact on health of the workers of a very fine material, silica-rich dust. Handling of the product should be an issue of study.

\section{Investment and Cost of Production range}

Table 2 shows a very preliminary comparison between the production and use of Portland cement and a lime-ash binder produced at a small scale. The main problems of the use of agricultural ashes in lime-ash system are:

- Small output of the production unit

- Limited use of the material in masonry applications, or substitution of Portland cement in nonstructural concrete.

- Relatively high energy consumption and carbon emissions, mainly due to the presence of lime in the formulation. The use of the ash in blended systems provides better results.

Table 2: comparison of different production schemes with agricultural ashes [55]

\begin{tabular}{|c|c|c|}
\hline & OPC & Lime-pozzolan binder \\
\hline Daily production & $500-1000$ ton & $0.5-0.9$ ton \\
\hline Initial investment & +150 millions $\$ U S$ & \$US12-15 thousand \\
\hline Uses & Universal & $\begin{array}{l}\text { Masonry, mineral } \\
\text { admixture }\end{array}$ \\
\hline Embodied energy & 3-6 MJ/kg & $3-4 \mathrm{MJ} / \mathrm{kg}$ \\
\hline $\mathrm{CO}_{2}$ emissions & $1-1.3 \mathrm{~kg} \mathrm{CO}_{2} / \mathrm{kg}$ cement & $0.4-0.6 \mathrm{~kg} \mathrm{CO} / 2 / \mathrm{kg}$ cement \\
\hline Sales price & \$US 100-180 & \$US 50-70 \\
\hline
\end{tabular}

\section{Simplified environmental assessment}

Calculating the carbon emissions of biomass is far more complex than for any other material, because the plant where the biomass originally comes from has been absorbing $\mathrm{CO}_{2}$ in the Photosynthesis during its entire life, and there is some avoided carbon in the equation [48] 
A simplified study for assessing the embodied energy of a lime-pozzolan binder was carried out years ago. The technology chosen was the small scale production of the material, collected as a waste in industrial facilities and mixed with locally produced lime. The embodied energy calculated was in the range of $4.47 \mathrm{MJ} / \mathrm{kg}$ of lime-pozzolan binder. If compared with Portland cement, with a variation between $3.2-4.8 \mathrm{MJ} / \mathrm{kg}$, no major improvement is observed. This is the result of the high environmental impact of using slaked lime in the production of the binder, which takes $80 \%$ of the overall emissions of the material. [57] Further, the issue of poor quality of rural burners could also contribute to increasing black smoke and impact greenhouse gas emissions [58]

\section{Barriers and incentives}

The lack of massive industrial applications has discouraged the adoption of standards covering the production and use of agricultural ashes as cement substitutes. There is an Indian Standard IS 4098, valid for lime-ash systems, which needs to be updated.

The process of understanding the impact of agricultural ashes on cement hydration is yet at a very early stage. Further fundamental research should be carried out to understand the main mechanisms behind the pozzolanic reaction and they can be improved.

Realistic market studies should be done, especially coupled with sustainability analysis that can provide answers to the questions raised in this report in terms of economic viability and environmental sustainability.

\section{Further research priorities}

To assess the interest of agricultural ashes as cementitious materials, research would be needed on the following issues:

- Structural transformation of amorphous silica during calcination. Ways of measuring the amount of amorphous material. Impact on reactivity

- Agricultural wastes ash as supplementary cementitious materials in in Portland blended cement hydration. Impact on pore structure and transport properties of the cementitious matrix. Applications on concrete and mortar. Performance of concrete matrix under the attack of aggressive substances.

- Energy efficiency throughout the entire process of firing agriculture waste, with the view of ultimately producing a reactive ash as by-product

- Use of low calorific biomass alternative fuels for cement production.

\section{Concluding Remarks}

Agriculture wastes are increasingly used as alternative sources of fuel for industrial processes, mainly in the sugar and rice industry. The availability of these materials is high, and their use as fuel is attractive to the industry from the economic viewpoint. Associated with this, large amounts of ashes are produced, which currently have little or no industrial use. The ashes of some agriculture wastes such as rice husks and sugar cane bagasse and leaves, if fired under controlled temperature and residence time, have proven to have pozzolanic properties, which would eventually enable their use as Supplementary Cementitious Materials. However, the current understanding of the mechanisms behind the hydration of these materials and the parameters influencing it are poor and implications such as long-term durability of concrete products is yet to be proven. Industrial processes in the food and construction industry have little interconnection; this could eventually discourage investments in new technology for recuperating the 
waste ashes. Furthermore, many vegetable ashes are currently used as soil fertilisers and in this sense their diversion into cement would have a negative environmental impact.

\section{References}

[1] United Nations Environmental Program (UNEP), Converting Waste Agricultural Biomass ito a Resource. Compendium of Technologies, 2009.

[2] UNEP, Using Agricultural Biomass Waste for Energy and Materials: Resource Conservation and GHG Emission reduction, A Biomass Assessment and Compendium of Technologies Project, (2007).

[3] V. Smil, Crop Residues: Agriculture's Largest Harvest, Bioscience. 49 (1999) 299-308.

[4] M. V Madurwar, R. V Ralegaonkar, S.A. Mandavgane, Application of agro-waste for sustainable construction materials : A review, Constr. Build. Mater. 38 (2013) 872-878. doi:10.1016/j.conbuildmat.2012.09.011.

[5] R. Méndez, M. V Borrachero, J. Payá, J. Monzó, Mechanical Strength of Lime-Rice Husk Ash Mortars : A Preliminary Study, Key Eng. Mater. 517 (2012) 495-499. doi:10.4028/www.scientific.net/KEM.517.495.

[6] J.F. Martirena, R.L. Day, B. Middendorf, Mixtures of Lime and Pozzolan for High Volume Portland Cement Replacement in Concrete, in: XVI Int. Conf. IBAUSIL, 2006: pp. 1373-1378.

[7] V. John Moacir, M.A. Cincotto, M. Gomes da Silva, Cinzas e Aglomerantes Alternativos, in: W.J. Freire, A.L. Beraldo (Eds.), Tecnol. E Mater. Altern. Constr., Freire, We, Unicamp, Editora da Rua Caio Graco Prado, 50 -Campus Unicamp Brasil, CEF 13083 Campinas, 2003: pp. 145-190.

[8] F. Martirena-Hernández, B. Middendorf, M. Gehrke, B. H., USE OF WASTES OF THE SUGAR INDUSTRY AS POZZOLANA IN LIME-POZZOLANA BINDERS: STUDY OF THE REACTION, Cem. Concr. Res. 28 (1998) 1525-1536.

[9] H. Biricik, F. Aköz, I. Berktay, A.N. Tulgar, Study of pozzolanic properties of wheat straw ash, Cem. Concr. Res. 29 (1999) 637-643.

[10] M. Frías, H. Savastano, E. Villar, M.I. Sánchez, S. Rojas de Santos, Characterization and properties of blended cement matrices containing activated bamboo leaf wastes, Cem. Concr. Compos. 34 (2012) 1019-1023. doi:10.1016/j.cemconcomp.2012.05.005.

[11] G.C. Cordeiro, R.D.T. Filho, E.M.R. Fairbairn, Effect of calcination temperature on the pozzolanic activity of sugar cane bagasse ash, Constr. Build. Mater. 23 (2009) 3301-3303. doi:10.1016/j.conbuildmat.2009.02.013.

[12] S.K. Agarwal, Pozzolanic activity of various siliceous materials, Cem. Concr. Res. 36 (2006) 1735-1739. doi:10.1016/j.cemconres.2004.06.025.

[13] D.G. Nair, A. Fraaij, A.A.K. Klaassen, A.P.M. Kentgens, A structural investigation relating to the pozzolanic activity of rice husk ashes, Cem. Concr. Res. 38 (2008) 861-869. doi:10.1016/j.cemconres.2007.10.004.

[14] P.K. Mehta, The chemistry and technology of cements made from rice-husk ash, in: Proc. UNIDO/ESCAP/RCTT Work. Rice-Husk Ash Cem. Peshawar, Pakistan, Reg. Cent. Technol. Transf. Banghalore, India, 1979: pp. 113-122.

[15] D.G. Nair, K.S. Jagadish, A. Fraaij, Reactive pozzolanas from rice husk ash : An alternative to 
cement for rural housing, Cem. Concr. Res. 36 (2006) 1062-1071.

doi:10.1016/j.cemconres.2006.03.012.

[16] P. Stroeven, D. Dai, E. Sabuni, Ash of vegetable waste used for economic production of low to high strength hydraulic binders, Fuel. 78 (1999) 153-159.

[17] J. Paya, J. Monzo, M.V. Borrachero, A. Mellado, L.M. Ordonez, Determination of amorphous silica in rice husk ash by a rapid analytical method, Cem. Concr. Res. 31 (2001) 227-231.

[18] E.. Villar-Cociña, M.F.. Rojas, E.V.. Morales, Sugar cane wastes as pozzolanic materials: Application of mathematical model, ACI Mater. J. 105 (2008) 258-264.

[19] M. Frias, E. Villar-Cociña, H. Savastano, Brazilian Sugar Cane Bagasse Ashes from the Cogeneration Industry as Active Pozzolans for Cement Manufacture, Cem. Concr. Compos. (2011). doi:10.1016/j.cemconcomp.2011.02.003

[20] Nguyen, T van, Ye, G , Breugel, K van, Fraay, ALA \& Bui, DD (2011). The study of using rice husk ash to produce ultra high performance concrete. Construction and Building Materials, 25(4), 2030-2035

[21] F. Martirena, B. Middendorf, R.L. Day, M. Gehrke, P. Roque, L. Martinez, S. Betancourt, Rudimentary, low tech incinerators as a means to produce reactive pozzolan out of sugar cane straw, Cem. Concr. Res. 36 (2006) 1056-1061.

[22] A.E. Teka, Utilization of Alternative Fuels in Cement Pyroprocessing : the Messebo Factory case study in Ethiopia, KTH School of Industrial Engineering and Management. Stockholm, 2015.

[23] P. Basu, Combustion and Gasification in Fluidized beds, J. Hazard. Mater. 138 (2006) 43606. doi:10.1016/j.jhazmat.2006.05.114.

[24] S. Grass, B. Jenkins, Biomass fueled fluidized bed combustion: atmospheric emissions, emission control devices and environmental regulations, Biomas and Bioenergy. 6 (1994) 243-260.

[25] E.A. Sondreal, S.A. Benson, J.P. Hurley, M.D. Mann, J.H. Pavlish, M.L. Swanson, G.F. Weber, C.J. Zygarlicke, Review of advances in combustion technology and biomass cofiring, Fuel Process. Technol. 71 (2001) 7-38.

[26] C.G. V. Ramanathan V., Global and regional climate changes due to black carbon, Nat. Geosci. 1 (2008) 221 - 227. doi:doi:10.1038/ngeo156.

[27] E. Villar-cociña, E. Valencia-Morales, R. González-Rodríguez, J. Hernández-Ruiz, Kinetics of the pozzolanic reaction between lime and sugar cane straw ash by electrical conductivity measurement : A kinetic - diffusive model, Cem. Concr. Res. 33 (2003) 517-524.

[28] R. Rajamma, R.J. Ball, L.A.C. Tarehlo, G.C. Allen, J.A. Labrincha, V.M. Ferreira, Characterisation and use of biomass fly ash in cement-based materials, J. Hazard. Mater. 172 (2009) 1049-1060. doi:10.1016/j.jhazmat.2009.07.109.

[29] S. Wansom, S. Janjaturaphan, S. Sinthupinyo, Characterizing pozzolanic activity of rice husk ash by impedance spectroscopy, Cem. Concr. Res. 40 (2010) 1714-1722.

doi:10.1016/j.cemconres.2010.08.013.

[30] CSI, WBCSD, Development of State of the Art-Techniques in Cement Manufacturing : Trying to Look Ahead ( CSI / ECRA-Technology Papers ) Final Draft 31 March 2009, (2009).

[31] R. Saidur, E.A. Abdelaziz, A. Demirbas, M.S. Hossain, S. Mekhilef, A review on biomass as a fuel for boilers, Renew. Sustain. Energy Rev. 15 (2011) 2262-2289. 
doi:10.1016/j.rser.2011.02.015.

[32] Smith R.G.: Rice Husk Ash Cement, Paper presented at the First International Seminar on Lime and Other Alternative Cements, Stoneleigh, Warwickshire, U.K, 9/11 Dec. 1991

[33] B. Middendorf, J.F. Martirena, M. Gehrke, R.L. Day, Lime Pozzolan Binders : an Alternative To Opc ? *, in: Int. Build. Lime Symp. Orlando, FL, March 9-11, 2005 Proc., National Lime Association, 2005: pp. 1-13.

[34] M. Frias, E. Villar-Cociña, H. Savastano, Brazilian Sugar Cane Bagasse Ashes from the Cogeneration Industry as Active Pozzolans for Cement Manufacture, Cem. Concr. Compos. (2011). doi:10.1016/j.cemconcomp.2011.02.003.

[35] M. Nehdi, J. Duquette, A. El Damatty, Performance of rice husk ash produced using a new technology as a mineral admixture in concrete, Cem. Concr. Res. 33 (2003) 1203-1210. doi:10.1016/S0008-8846(03)00038-3.

[36] S. Jala, D. Goyal, Fly ash as a soil ameliorant for improving crop production - a review, Bioresour. Technol. 97 (2006) 1136-1147. doi:10.1016/j.biortech.2004.09.004.

[37] M. Maljanen, M. Liimatainen, J. Hytönen, The effect of granulated wood-ash fertilization on soil properties and greenhouse gas ( GHG ) emissions in boreal peatland forests, Boreal Environ. Res. 6095 (2014) 295-309.

[38] H. Pan, T. Eberhardt, OF WOOD AND ASSESSMENT FOR ITS APPLICATION AS A, Bioresources. 6 (2011) 3987-4004.

[39] Z. Tan, A. Lagerkvist, Phosphorus recovery from the biomass ash : A review, Renew. Sustain. Energy Rev. 15 (2011) 3588-3602. doi:10.1016/j.rser.2011.05.016.

[40] J.M. Paris, J.G. Roessler, C.C. Ferraro, H.D. Deford, T.G. Townsend, A Review of Waste Products Utilized as Supplements to Portland Cement in Concrete, J. Clean. Prod. (2016). doi:10.1016/j.jclepro.2016.02.013

[41] K. Ganesan, Rice husk ash blended cement : Assessment of optimal level of replacement for strength and permeability properties of concrete, Constr. Build. Mater. 22 (2008) 1675-1683. doi:10.1016/j.conbuildmat.2007.06.011.[42] E.S. Berodier, K.L. Scrivener, Evolution of the pore structure in blended systems, Cem. Concr. Res. 73 (2015) 25-35

[43] P.K. Mehta, HIGHLY DURABLE CEMENT PRODUCTS CONTAINING SILICEOUS ASHES, USOO5346548A, 1994.

[44] C. Rhen, O. Ohman, R. Gref, I. Waesterlung, Effect of raw material composition in woody biomass pellets on combustion characteristics, Biomass and Bioenergy. 31 (2007) 66-72. doi:10.1016/j.biombioe.2006.06.016.

[45] P. De Filippis, C. Borgianni, M. Paolucci, F. Pochetti, Gasification process of Cuban bagasse in a two-stage reactor, Biomas and Bioenergy. 27 (2004) 247-252. doi:10.1016/j.biombioe.2003.11.009.

[46] L. Maria, S. De Souza, E. De Moraes, R. Fairbairn, R. Dias, T. Filho, G. Chagas, INFLUENCE OF INITIAL CaO/SiO2 RATIO ON THE HYDRATION OF RICE HUSK ASH-Ca(OH)2 AND SUGAR CANE BAGASSE ASH-Ca(OH)2 PASTES, Quim. Nova,. 37 (2014) 1600-1605. doi:http://dx.doi.org/10.5935/0100-4042.20140258.

[47] A. Kristin, P. Raymer, A comparison of avoided greenhouse gas emissions when using different 
kinds of wood energy, Biomass and Bioenergy. 30 (2006) 605-617. 4844]

https://www.worldenergy.org/data/resources/resource/biomass/, https://www.worldenergy.org/data/resources/resource/biomass/, (n.d.).

[49] R. Slade, R. Saunders, R. Grss, A. Bauen, Energy from biomass : the size of the global resource An assessment of the evidence that biomass can make a major contribution to future global energy supply, London, 2011.

[50] A.C. Alonso, B.G. Moreda, A.V. Delgado, Generación de electricidad a partir de bagazo en Cuba, in: Mem. - Reun. Reg. Sobre Generación Electr. a Partir Biomasa, 1995.

[51] V.M. Malhortra, Role of Supplementary Cementing Materials in Reducing greenhouse gas emissions., in: O. Gjorv, K. Sakai (Eds.), Concr. Technol. a Sustain. Dev. 21st Century, E\&FN Spon, London, 2000: pp. 226-235.

[52] J. Payá, J. Monzó, M.V. Borrrachero, Outstanding aspects of the use of Rice Husk Ash and simila agrowastes in the preparation of binders, in: I Pro-Africa Conf. Non Conv. Build. Mater. Based Agriultural Wastes., Pirassunnunga-SP, 2010.

[53] J.K. Ã, M. Junginger, Development of fluidized bed combustion - An overview of trends , performance and cost, Prog. Energy Combust. Sci. 33 (2007) 19-55. doi:10.1016/j.pecs.2006.07.001.

[54] L.O. Ettu, J.C. Ezeh, U.C. Anya, K.C. Nwachukwu, K.O. Njoku, Strength Of Ternary Blended Cement Concrete Containing Afikpo Rice Husk Ash And Saw Dust Ash, Int. J. Eng. Sci. Invent. 2 (2013) 38-42.

[55] L.M. Fernández, R.Q. Puchol, J. Fernando, M. Hernández, Aglomerante puzolánico formado por cal y ceniza de paja de caña de azúcar : la influencia granulométrica de sus componentes en la actividad aglomerante Pozzolanic binder constituted by lime and cane sugar straw ash : the granulometric influence of its com, Rev. Ing. Construcción. 22 (2007) 113-122. www.ing.puc.cl/ric.

[56] J.F. Martirena, B. Middendorf, R.L. Day, Pozzolans out of wastes from the sugar industry, in: Int. Conf. Cem. Chem. ICCC, Montreal, 2007: pp. 1-10.

[57] K. Blanco, Analysis of Embodied Energy Pozzolanic Cement CP-40. Case Study Nicaragua, 2001.

[58] V. Ramanathan, G. Carmichael, Global and regional climate changes due to black carbon, Constr. Build. Mater. 22 (2008) 1675-1683. 